Marquette University

e-Publications@Marquette

Psychology Faculty Research and Publications

Psychology, Department of

$1-1-2011$

Advancing Our Knowledge of ADHD in Latino Children: Psychometric and Cultural Properties of Spanish-Versions of Parental/Family Functioning Measures

Lauren M. Haack

Marquette University

Alyson C. Gerdes

Marquette University, alyson.gerdes@marquette.edu

Brian W. Schneider

Marquette University

Gabriela Dieguez Hurtado

Marquette University

Accepted version. Journal of Abnormal Child Psychology, Volume 39, No. 1 (2011): 33-43. DOI: (C) 2011 Springer. Used with permission.

Shareable Link. Provided by the Springer Nature SharedIt content-sharing initiative. 


\title{
Advancing Our Knowledge of ADHD in Latino Children: Psychometric and Cultural Properties of Spanish- Versions of Parental/Family Functioning Measures
}

\author{
Lauren M. Haack \\ Psychology Department, Marquette University \\ Milwaukee, WI \\ Alyson C. Gerdes \\ Psychology Department, Marquette University \\ Milwaukee, WI \\ Brian W. Schneider \\ Psychology Department, Marquette University \\ Milwaukee, WI \\ Gabriela Dieguez Hurtado \\ Sixteenth Street Community Health Center \\ Milwaukee, WI
}




\begin{abstract}
The lack of available Spanish versions of assessment measures contributes to insufficient research and underutilization of mental health services for Latino children with Attention-Deficit/Hyperactivity Disorder (ADHD). Thus, the goal of the current study was to examine the psychometric and cultural properties of several Spanish versions of parental/family functioning measures commonly used in comprehensive ADHD assessments (i.e., the Parenting Sense of Competence Scale, Alabama Parenting Questionnaire, and Confusion, Hubbub, and Order Scale). Participants included 68 Spanish-speaking, Latino parents in Southeast Wisconsin. In general, the Spanish translations of the measures demonstrated good reliability and validity. Furthermore, the psychometrically-sound measures were significantly related to acculturation as predicted, suggesting that the scales are not only psychometrically valid, but also culturally valid for use with Spanish-speaking, Latino families.
\end{abstract}

Keywords: Clinical child psychology, Multicultural psychology, Assessment, ADHD, Acculturation

The lack of available and appropriate mental health services for Latino youth in the United States is a significant concern (for full reviews, see Callejas et al. 2006; Flores et al. 2002; U.S. Department of Health and Human Services 2001). Recommendations put forth by Callejas et al. (2006) emphasize that in order to provide quality mental health services to Latino youth, we must begin with culturally and linguistically appropriate assessments. Many childhood mental health disorders, such as Attention-Deficit/Hyperactivity Disorder $(A D H D)$ require comprehensive assessments for adequate treatment planning aimed at treating not only the child's functional problems, but also commonly-occurring parental/family problems (Pelham et al. 2005). Unfortunately, many of the parental/family functioning measures needed to complete such an assessment have not been translated or validated in Spanish. Thus, the primary objective of the current study was to establish the psychometric and cultural properties of measures assessing parenting efficacy, parenting behavior, and family chaos.

\title{
Background and Significance
}

The Latino population is one of the fastest growing ethnic minority groups in the country, expected to comprise one quarter of the youth population by 2050 (U.S. Census Bureau 2000). There are a number of aspects related to the underutilization of mental health services by Latinos, both practical and cultural. The most common 
practical barriers to Latinos seeking and receiving mental health care include lack of insurance, low socioeconomic status (SES), limited parental education, and transportation problems (e.g., Alegría et al. 2007; for reviews, see U.S. Department of Health and Human Services 2001; Vega and Lopez 2001). There are a number of cultural barriers to care as well, such as immigration and citizenship status, culturallybased negative emotions and beliefs toward mental health treatment, unfamiliarity and distrust of providers, and lack of appropriate bilingual/bicultural providers (Callejas et al. 2006; Flores et al. 2002; Peifer et al. 2000). Within these cultural aspects, language is one of the most consistently reported barriers to Latinos seeking and receiving mental health care (e.g., Alegría et al. 2007), which is likely due to the fact that limited English fluency makes it difficult for Latino parents to identify appropriate services for their children, communicate with professionals, and understand assessment and treatment procedures.

In addition to contributing to the underutilization of mental health services, language serves as a barrier to advancing research about this underserved population. Flores et al. (2002) reported that for both convenience and practicality, many epidemiological and treatment outcome studies screen for and exclude all individuals who do not speak English, which has resulted in a lack of research examining prevalence rates and treatment outcomes for Latino youth (Callejas et al. 2006; Peifer et al. 2000). The few studies that have been completed show that Latino youth are at higher risk for several mental health problems (Kataoka et al. 2002; Yeh et al. 2003), including behavioral disorders, such as ADHD (Flores et al. 2002; U.S. Department of Health and Human Services 2001). Given the frequency and long-lasting impact of ADHD (American Psychiatric Association 2000; Smith et al. 2006; Pelham 2002), as well the higher risk for behavioral disorders in Latino youth, it seems particularly important to devote more research to examining ADHD in Latinos.

\section{Attention-Deficit/Hyperactivity Disorder (ADHD) and Parental/Family Functioning}

In addition to symptoms of inattention and hyperactivityimpulsivity, children with ADHD frequently exhibit additional problems

Journal of Abnormal Child Psychology, Vol 39, No. 1 (2011): pg. 33-43. DOI. This article is @ Springer and permission has been granted for this version to appear in e-Publications@Marquette. Springer does not grant permission for this article to be further copied/distributed or hosted elsewhere without the express permission from Springer. 
that interfere with their social, educational, and emotional development. Such difficulties typically include comorbid behavioral and learning disorders, peer problems, and parental/family problems (for full reviews, see Chronis et al. 2004; Smith et al. 2006; Johnston and Mash 2001; Pelham 2002; Pelham et al. 2005; Reddy and de Thomas 2007). Decades of research have documented the prevalence of parental/family problems in families of children with ADHD. Children with ADHD experience more negative and fewer positive interactions with their parents than comparison children, resulting in less positive relationships (Dupaul et al. 2001; Keown and Woodward 2002). In addition, parents of children with ADHD display higher rates of ADHD, depression, and substance abuse disorders than comparison parents (Chronis et al. 2003; Cunningham and Boyle 2002; Schill et al. 1999). They also report more parenting stress (Dupaul et al. 2001; Johnston and Mash 2001; Shelton et al. 1998), lower parental satisfaction and efficacy (Cunningham and Boyle 2002; Shelton et al. 1998), and more marital discord than parents of comparison children (Murphy and Barkley 1996; Shelton et al. 1998). Finally, families of children with ADHD are more likely to experience family conflict and adversity (Cunningham and Boyle 2002; Murphy and Barkley 1996; Schill et al. 1999).

\section{Comprehensive Assessment of ADHD}

Given the complexity of making an ADHD diagnosis and the need to assess for all additional difficulties that commonly present with ADHD, such as comorbid disorders, peer problems, and parental/family problems, an ADHD assessment must be comprehensive. Thus, assessment guidelines for ADHD emphasize obtaining information using multiple methods (e.g., interviews, questionnaires, and observations), multiple informants (e.g., parents and teachers), and multiple contexts (e.g., school and home; for full reviews, see Pelham 2002; Pelham et al. 2005; Reddy and de Thomas 2007). In order to assess parental/family functioning, measures examining parenting stress, efficacy, and behavior, as well as family chaos are often included. Unfortunately, with few exceptions (e.g., Parenting Stress Inventory-Short Form; Solis and Abidin 1991), many of the parental/family functioning measures are not available in Spanish,

Journal of Abnormal Child Psychology, Vol 39, No. 1 (2011): pg. 33-43. DOI. This article is @ Springer and permission has been granted for this version to appear in e-Publications@Marquette. Springer does not grant permission for this article to be further copied/distributed or hosted elsewhere without the express permission from Springer. 
which makes it impossible to provide Spanish-speaking only, Latino families with a culturally and linguistically appropriate assessment.

\section{Examination of Psychometric Properties}

In order to establish the psychometric properties of a measure, reliability and validity typically are examined. While there are many ways to measure a test's reliability, the most popular and recommended is Cronbach's measure of internal consistency (Cronbach 1951), with an alpha value of 0.70 or greater as desirable (Cortina 1993; Sattler 2001). One of the most common types of validity examined is construct validity, which can be determined by examining the correlation between a test and other theoreticallyrelated measures (Cronbach and Meehl 1955; Messick 1995). Determining construct validity is essential to ensure that test results can be accurately interpreted and appropriate inferences can be made (Clark and Watson 1995; Messick 1995; Sattler 2001).

\section{Examination of Cultural Properties}

In addition to establishing psychometric properties, it also seems important to establish a translated measure's cultural properties. The limited research available suggests that when Latino families (who traditionally display more collectivist and hierarchical family processes) come into contact with more individualistic and egalitarian cultures, the degree to which they adapt and acculturate greatly affects their parental/family functioning (for reviews see Bornstein and Cote 2006; Mio et al. 2006). For example, parents who remain loyal to Latino values, such as "familism" and "respeto" tend to emphasize the closeness of the family, as well as structured rules and boundaries (Miranda et al. 2006; Miranda et al. 2000; Rodriguez et al. 2007). These parents also keep discipline strategies consistent and often favor spanking and other forms of corporal punishment (see Halgunseth et al. 2006 for a review; Monzo and Rueda 2006). In comparison, parents who develop strong associations with mainstream Anglo views tend to value independence and autonomous behavior over the closeness of the family and place less emphasis on rigid discipline and hierarchy among family members (Fuligni 1998; Okagaki and Sternberg 1993). While the Anglo values of independence

Journal of Abnormal Child Psychology, Vol 39, No. 1 (2011): pg. 33-43. DOI. This article is @ Springer and permission has been granted for this version to appear in e-Publications@Marquette. Springer does not grant permission for this article to be further copied/distributed or hosted elsewhere without the express permission from Springer. 
and autonomy may lead to some aspects of positive child adjustment, they also may lead to poorer parental monitoring and more inconsistent discipline relative to the rigid discipline and family hierarchy seen in families who remain loyal to traditional Latino values (Halgunseth et al. 2006). Additionally, Anglo-oriented families often experience acculturation stress, which may lead to more conflict and chaos within the family (Miranda et al. 2006; Miranda et al. 2000; Smokowski et al. 2007). Thus, examining the association between acculturation and parental/family functioning is important, because it will provide evidence that the measures are not only linguistically and psychometrically appropriate, but also culturally appropriate.

\section{Current Study}

The lack of available Spanish versions of parental/family functioning measures affects the underutilization of mental health services by Latino children with ADHD. Thus, the goal of the current study was to establish both the psychometric and cultural properties of several Spanish versions of measures commonly used in comprehensive ADHD assessments. Specifically, the present study examined the psychometric and cultural properties of the Spanish translations of the Parenting Sense of Competence (PSOC; as cited in Johnston and Mash 1989), Alabama Parenting Questionnaire (APQ; Shelton et al. 1996), and Confusion, Hubbub, and Order Scale (CHAOS; Dumas et al. 2005).

It was predicted that the Spanish translations of the PSOC, APQ, and $\mathrm{CHAOS}$ would demonstrate reliabilities (i.e., internal consistencies) similar to their English counterparts. It also was predicted that they would demonstrate good convergent validity (i.e., they would correlate with theoretically-related measures). Specifically, it was predicted that the PSOC and APQ subscales of Involvement and Positive Parenting would be negatively correlated with the PSI-SF and the broadband externalizing scale of the CBCL/6-18, whereas the CHAOS and APQ subscales of Poor Monitoring/Supervision, Inconsistent Discipline, and Corporal Punishment would be positively correlated with the PSI-SF and the broadband externalizing scale of the CBCL/6-18. It also was predicted that the Spanish translations of the APQ, PSOC, and CHAOS would demonstrate good concurrent validity. Specifically, it was 
expected that they would appropriately distinguish problem children from non-problem children as measured by the CBCL/6-18. It also was predicted that the Spanish translations of the PSOC, APQ, and CHAOS would be correlated with theoretically-related measures of Anglo and Mexican orientation, as measured by the Acculturation Rating Scale For Mexican Americans-II (ARSMA-II; Cuéller et al. 1995). Specifically, it was predicted that Mexican orientation would be positively related to the PSOC and APQ subscales of Involvement and Corporal Punishment, whereas Anglo orientation would be positively related to the $\mathrm{CHAOS}$ and APQ subscales of Poor Monitoring/Supervision and Inconsistent Discipline.

\section{Method}

\section{Preliminary Work}

In preparation for the current study, the measures of interest (the PSOC, APQ, and CHAOS) were translated from English to Spanish. Following recommendations by Brislin (1970; Brislin et al. 1973), the PSOC and CHAOS were forward and back translated with one individual forward translating the measures from English to Spanish, and another individual back translating the measures to English. Following each back translation, comparisons were made between the original English and back translated English and modifications were made when discrepancies arose. As a final check, a third bilingual individual reviewed the measures and additional modifications were made. The APQ was translated by a team at the University of North Carolina who also employed both forward and back translation. Following the translations, the reading level of each measure was established by using the Crawford Readability Graph (Crawford 1984), which is based on the Fry-type readability graphs (Fry 1968, 1977), and the TxReadability program (Accessibility Institute at UT-Austin), which is based on the Flesch Reading Ease formula (Flesch 1948). Scores ranged from fourth to sixth grade and were similar to the estimated reading levels of the English versions. 


\section{Participants}

Participants included 68 Spanish-speaking, Latino parents in Southeast Wisconsin. Parents needed to be able to read Spanish at a fourth grade level and have a child between the ages of 5 and 12 years of age. ${ }^{1}$ Participants primarily included married mothers of Mexican origin with varied socioeconomic backgrounds; mean age was 33.69 years $(\mathrm{SD}=5.78)$. Children were predominantly boys with a mean age of 7.96 years $(S D=2.01)$. Complete demographic information may be found in Table 1 .

Table 1 Parent and Child Demographics

\begin{tabular}{|c|c|c|}
\hline \multicolumn{3}{|l|}{ Parent demographics } \\
\hline Age, $M(S D)$ & \multicolumn{2}{|c|}{$33.69 \mid(5.78)$} \\
\hline \multicolumn{3}{|l|}{ Gender, n (\%) } \\
\hline Male & 10 & $(14.70)$ \\
\hline Female & 58 & $(85.30)$ \\
\hline \multicolumn{3}{|l|}{ Marital Status, n (\%) } \\
\hline Married & 49 & $(72.10))$ \\
\hline Unmarried & 19 & $(27.90)$ \\
\hline \multicolumn{3}{|l|}{ Education, n (\%) } \\
\hline Less than high school or some high s & |34 & $(50.00)$ \\
\hline Graduated high school or GED & 12 & $(17.60)$ \\
\hline Some college or specialized training & 13 & $(19.10)$ \\
\hline College or graduate degree & 9 & $(13.24)$ \\
\hline \multicolumn{3}{|l|}{ Income, n (\%) } \\
\hline Less than $\$ 20,000$ & 27 & $(57.45)$ \\
\hline$\$ 20,001-40,000$ & 15 & (31.19) \\
\hline$\$ 40,000-60,000$ & 0 & $(0.00)$ \\
\hline$\$ 60,001-80,000$ & 5 & $(10.64)$ \\
\hline \multicolumn{3}{|l|}{ Country of origin, $\mathrm{n}(\%)$} \\
\hline Mexico & 58 & $(85.30)$ \\
\hline Puerto Rico & 6 & $(8.80)$ \\
\hline Other & 3 & $(4.50)$ \\
\hline \multicolumn{3}{|l|}{ Time in US, n (\%) } \\
\hline Less than 6 years & 14 & $(20.58)$ \\
\hline $6-10$ years & 26 & $(38.23)$ \\
\hline
\end{tabular}

Journal of Abnormal Child Psychology, Vol 39, No. 1 (2011): pg. 33-43. DOI. This article is @ Springer and permission has been granted for this version to appear in e-Publications@Marquette. Springer does not grant permission for this article to be further copied/distributed or hosted elsewhere without the express permission from Springer. 
NOT THE PUBLISHED VERSION; this is the author's final, peer-reviewed manuscript. The published version may be accessed by following the link in the citation at the bottom of the page.

\begin{tabular}{|l|l|l|}
\hline More than 10 years & 26 & $(38.23)$ \\
\hline Language, $\mathrm{n}(\%)$ & 25 & $(36.80)$ \\
\hline Only Spanish & 29 & $(42.60)$ \\
\hline Primarily Spanish, some English & 14 & $(20.60)$ \\
\hline Bilingual & \multicolumn{3}{|l|}{} \\
\hline Child demographics & 7.96 & $(2.01)$ \\
\hline Age, M (SD) & \multicolumn{3}{|l|}{} \\
\hline Gender, n (\%) & 41 & $(60.30)$ \\
\hline Boys & 27 & $(39.70)$ \\
\hline Girls & \multicolumn{3}{|l}{} \\
\hline
\end{tabular}

$N=68$

\section{Procedure}

Recruitment. Following approval from the Institutional Review Board, four bilingual elementary schools sent a parent letter describing the project to all Latino families who had a child in first through sixth grade. Interested parents were asked to complete and return the enclosed postcard that included their contact information. In addition, Latino families from three of the four schools received automated phone calls from the school describing the project and encouraging interested parents to call the school. A bilingual research assistant called all interested parents to set up an appointment. Toward the end of data collection, schools also sent flyers home reminding families that the project was coming to a close and informing them that walkins were welcome during data collection times. Finally, information tables staffed by bilingual research assistants were set up at several school-sponsored, family events (for a more detailed description of recruitment, see Haack et al. 2010).

Data Collection. Sessions occurred at the end of the school day or at school-sponsored events at the schools and lasted approximately $1 \mathrm{~h}$. Once parents signed a consent form in Spanish, they independently completed the packet of measures and were advised to seek help for clarification or questions from bilingual research assistants trained in the administration of the measures. Once completed, parents received a $\$ 10$ girt card for their participation. ${ }^{2}$ 
NOT THE PUBLISHED VERSION; this is the author's final, peer-reviewed manuscript. The published version may be accessed by following the link in the citation at the bottom of the page.

\section{Measures}

Measures of interest included a demographic form, Spanish translations of the PSOC, APQ, and CHAOS, as well as Spanish translations of the Parenting Stress Inventory-Short Form (PSI-SF; Abidin 1982; Spanish translation by Solis and Abidin 1991), Child Behavior Checklist/6-18 (CBCL/6-18; Achenbach and Rescorla 2001; Spanish translation by Rubio-Stipec et al. 1990), and Acculturation Rating Scale For Mexican Americans-II (ARSMA-II; Cuellar et al. 1995).

Demographic Form. The demographic form was created for this study and asked questions about parental ethnicity, education, occupation, number of parents living in the home, and number of children in the family.

Parenting Sense of Competence Scale (PSOC; GibaudWallston and Wandersman 1978, as cited in Johnston and Mash 1989). The Parenting Efficacy subscale of the PSOC is a 7-item, parent-report measure of parenting efficacy. The mean of the items is calculated with higher scores indicating higher parenting efficacy. Johnston and Mash (1989) reported good internal consistency (0.76) and good divergent construct validity for the English version.

Alabama Parenting Questionnaire (APQ; Shelton et al. 1996). The APQ is a 42-item measure assessing parenting practices that can be completed by parents or children. Sums of items are created for five parenting behaviors (Involvement, Positive Parenting, Poor Monitoring/Supervision, Inconsistent Discipline, and Corporal Punishment) with higher scores representing more of that type of parenting. Internal consistencies for the English version range from 0.55 (Corporal Punishment) to 0.77 (Positive Parenting); good convergent and discriminate validity, as well as concurrent criterion validity have been established (Dadds et al. 2003; Essau et al. 2006; Shelton et al. 1996).

Confusion, Hubbub, and Order Scale (CHAOS; Matheny et al. 1995). The CHAOS is a 15-item, parent-report measure assessing environmental chaos in the home; higher scores indicate greater

Journal of Abnormal Child Psychology, Vol 39, No. 1 (2011): pg. 33-43. DOI. This article is @ Springer and permission has been granted for this version to appear in e-Publications@Marquette. Springer does not grant permission for this article to be further copied/distributed or hosted elsewhere without the express permission from Springer. 
reported chaos. Matheny et al. (1995) reported good internal consistency (0.79) for the English version, and Dumas et al. (2005) demonstrated good convergent construct validity.

\section{Spanish translation of the Parenting Stress Inventory-} Short Form (PSI-SF; Abidin 1982; Spanish translation by Solis and Abidin 1991). The PSI-SF is a 36-item, parent-report measure of parenting stress with higher scores indicating more stress. In addition to an overall parenting stress score, which was used in the current study, three subscales (Parental Distress, Parent/Child Dysfunctional Interaction, and Difficult Child) can be computed. Solis and Abidin (1991) examined the internal consistency and validity of the Spanish translation. They reported good internal consistency for total parenting stress (0.94) and good concurrent criterion validity.

\section{Spanish translation of the Child Behavior Checklist/6-18} (CBCL/6-18; Achenbach and Rescorla 2001; Spanish translation by Rubio-Stipec et al. 1990). The CBCL/6-18 is a 112 -item, parent-report measure of child behaviors. It results in three broadband scores for total, internalizing, and externalizing problems, as well as a variety of narrowband scores with higher scores indicating greater severity. Rubio-Stipec et al. (1990) examined the Spanish translation and found good ranges of internal consistency (0.89-0.94) on the broadband externalizing scale, which was the only one used in the current study. Good convergent construct validity also was reported.

\section{The Acculturation Rating Scale for Mexican Americans-}

II (ARSMA-II; Cuéller et al. 1995). The ARSMA-II is a 30-item selfreport measure available in Spanish, which assesses acculturation bidimensionally in terms of language, ethnic identity, and ethnic interaction. It results in two subscales with higher scores representing higher orientation/affiliation with that culture. The Mexican Orientation Subscale (MOS) has 17 items and measures orientation toward the Mexican culture, whereas the Anglo Orientation Subscale (AOS) has 13 items and measures orientation toward the Anglo culture. Cuéller et al. (1995) reported good internal consistency for both subscales (MOS 0.88 and AOS - 0.83).

Journal of Abnormal Child Psychology, Vol 39, No. 1 (2011): pg. 33-43. DOI. This article is @ Springer and permission has been granted for this version to appear in e-Publications@Marquette. Springer does not grant permission for this article to be further copied/distributed or hosted elsewhere without the express permission from Springer. 


\section{Results}

\section{Psychometric Properties}

PSOC. In order to examine the internal consistency of the Spanish translation of the PSOC, Cronbach's alpha was computed and revealed good internal consistency (0.80), which is similar to its English counterpart (see Table 2). In an effort to determine convergent validity, correlations between the PSOC and PSI-SF, as well as the broadband externalizing scale of the $\mathrm{CBCL} / 6-18$ were examined. As shown in Table 3, significant negative correlations with the PSI-SF $(r=-0.32, p<0.01)$ and broadband externalizing scale of the CBCL/6$18(r=-0.32, p<0.01)$ emerged. In order to investigate the concurrent validity, a binary logistic regression examining the likelihood of the PSOC in distinguishing problem from non-problem children as measured by borderline or clinical elevations (i.e., T scores of 59 or higher) on the broadband externalizing scale of the CBCL/6-18 was employed. Results of the model did not reveal a significant ability of the PSOC to reliably distinguish problem from non-problem children (see Table 4).

Table 2 Cronbach's Alpha Levels of Reliability

\begin{tabular}{|l|c|l|}
\hline & a & \multicolumn{1}{|c|}{$\begin{array}{c}\text { Reported a for English } \\
\text { versions }\end{array}$} \\
\hline PSOC & $0.80^{\mathrm{a}}$ & 0.76 \\
\hline APQ involvement & $0.70^{\mathrm{a}}$ & 0.75 \\
\hline APQ positive parenting & $0.70^{\mathrm{a}}$ & 0.77 \\
\hline $\begin{array}{l}\text { APQ poor } \\
\text { monitoring/supervision }\end{array}$ & 0.61 & 0.59 \\
\hline APQ inconsistent discipline & 0.56 & 0.73 \\
\hline APQ corporal punishment & 0.60 & 0.55 \\
\hline CHAOS & $0.79^{\mathrm{a}}$ & 0.79 \\
\hline
\end{tabular}

andicates good reliability with $a \geq 0.70$. Cronbach's alpha value for the English version of the CHAOS is from Matheny et al. 1995, Cronbach's alpha value for the English version of the PSOC is from Johnston and Mash 1989, and Cronbach's alpha values for the English version of the APQ are from Dadds et al. 2003 
Table 3 Correlations for the PSOC, APQ, and CHAOS with the PSI-SF and $\mathrm{CBCL} / 6-18$

\begin{tabular}{|l|l|l|}
\hline & PSI-SF & CBCL/6-18 externalizing \\
\hline PSOC & $-0.32^{* *}$ & $-0.32^{* *}$ \\
\hline APQ involvement & -0.23 & $-0.41^{* *}$ \\
\hline APQ positive parenting & $-0.37^{* *}$ & $-0.50^{* * *}$ \\
\hline APQ poor monitoring/supervision & 0.09 & 0.04 \\
\hline APQ inconsistent discipline & 0.07 & 0.01 \\
\hline APQ corporal punishment & 0.18 & $0.36^{* *}$ \\
\hline CHAOS & $0.50^{* * *}$ & $0.40^{* * *}$ \\
\hline
\end{tabular}

${ }^{* *} p \leq 0.01,{ }^{* * *} p \leq 0.001$

Table 4 Logistic Regressions Predicting Externalizing Behaviors as Measured by the $\mathrm{CBCL} / 6-18$

\begin{tabular}{|l|l|l|l|l|l|l|l|l|l|l|}
\hline & & & & & & $\begin{array}{c}\mathbf{9 5 \%} \\
\mathbf{C . I}\end{array}$ & & & \\
\hline & $\boldsymbol{B}$ & S.E. & Wald & df & $\boldsymbol{p}$ & Odds & $\begin{array}{c}\text { for Odds } \\
\text { Ratio }\end{array}$ & $\begin{array}{l}\text { Cox \& } \\
\text { Snell }\end{array}$ & Nagelkerke \\
\hline & & & & & & Ratio & Lower & Upper & $\mathbf{R}^{2}$ & $\mathbf{R}^{\mathbf{2}}$ \\
\hline PSOC & -0.32 & 0.73 & 0.17 & 1 & 0.70 & 0.74 & 0.26 & 1.91 & 0.01 & 0.01 \\
\hline APQ involvement & $-0.26^{*}$ & 0.12 & 4.57 & 1 & 0.03 & 0.77 & 0.75 & 1.01 & 0.08 & 0.22 \\
\hline APQ positive parenting & $-0.42^{* *}$ & 0.18 & 5.08 & 1 & 0.02 & 0.67 & 0.61 & 0.96 & 0.11 & 0.30 \\
\hline $\begin{array}{l}\text { APQ poor } \\
\text { monitoring/supervision }\end{array}$ & 0.09 & 0.87 & 0.97 & 1 & 0.33 & 1.09 & 0.91 & 1.16 & 0.01 & 0.04 \\
\hline APQ inconsistent discipline & -0.09 & 0.13 & 0.47 & 1 & 0.49 & 0.92 & 0.89 & 1.22 & 0.01 & 0.02 \\
\hline APQ corporal punishment & $0.78^{* * *}$ & 0.30 & 6.85 & 1 & 0.01 & 2.20 & 1.09 & 2.56 & 0.11 & 0.30 \\
\hline CHAOS & $0.15^{*}$ & 0.07 & 4.68 & 1 & 0.03 & 1.17 & 1.02 & 1.23 & 0.09 & 0.26 \\
\hline
\end{tabular}

${ }^{*} p \leq 0.05,{ }^{* *} p \leq 0.01,{ }^{* * *} p \leq 0.001$

APQ. As shown in Table 2, the Spanish translation of the APQ subscales (Involvement, Positive Parenting, Poor Monitoring/Supervision, Inconsistent Discipline, and Corporal Punishment) revealed variable internal consistency ranging from $0.56-$ 0.70 . With the exception of Inconsistent Discipline, all of these levels are similar to their English counterparts. Correlations examining convergent validity revealed that Positive Parenting was negatively correlated with the PSI-SF $(r=-0.37, p<0.01)$, both Positive Parenting and Involvement were negatively correlated with the 
broadband externalizing scale of the CBCL/6-18 $(r=-0.50, p<0.001$; $r=-0.41, p=0.001$, respectively), and Corporal Punishment was positively correlated with the broadband externalizing scale of the CBCL/6-18 ( $r=0.36, p<0.01$; see Table 3$)$. Binary logistic regressions examining concurrent validity revealed that Involvement $\left(X^{2}=5.62\right.$, $p<0.05)$, Positive Parenting $\left(x^{2}=7.59, p<0.01\right)$, and Corporal Punishment $\left(X^{2}=7.59, p<0.01\right)$ reliably distinguished between children displaying clinically significant externalizing problems (see Table 4). Examination of Cox and Snell and Nagelkerke $\mathrm{R}^{2}$ values demonstrate that between $8 \%$ and $30 \%$ of the variability in the presence of externalizing problems was explained by these measures. Examination of odds ratios indicate that parents who reported lower levels of Involvement and Positive Parenting were 0.77 and 0.67 times less likely to report their child as clinically elevated for externalizing problems, respectively, whereas parents who reported higher levels of Corporal Punishment were 2.20 times more likely to report their child as clinically elevated for externalizing problems.

CHAOS. Finally, examination of the internal consistency of the Spanish translation of the CHAOS revealed good internal consistency (0.79), which is similar to its English counterpart (see Table 2). Examination of convergent validity revealed significant positive correlations with the PSI-SF $(r=0.50, p<0.001)$ and broadband externalizing scale of the CBCL/6-18 ( $r=0.40, p=0.001$; see Table 3 ). Similar to the PSOC and $A P Q$, a binary logistic regression was employed to examine convergent validity. As shown in Table 4, results of the model suggest that the CHAOS reliably distinguished between children displaying clinically significant externalizing problems $\left(X^{2}=6.64, p=0.01\right)$. Examination of Cox and Snell and Nagelkerke $\mathrm{R}^{2}$ values demonstrate that between $9 \%$ and $26 \%$ of the variability in the presence of externalizing problems was explained by this measure, and examination of odds ratios indicate that parents who reported higher levels of CHAOS were 1.17 times more likely to report their child as clinically elevated for externalizing problems.

\section{Cultural Properties}

Due to the nature of the scale, cultural properties as measured by the ARSMA-II were only examined with parents of Mexican descent

Journal of Abnormal Child Psychology, Vol 39, No. 1 (2011): pg. 33-43. DOI. This article is @ Springer and permission has been granted for this version to appear in e-Publications@Marquette. Springer does not grant permission for this article to be further copied/distributed or hosted elsewhere without the express permission from Springer. 
$(N=58)$. Examination of means and standard deviations of the linear AOS and MOS indicated that the current sample reported lower Anglo orientation and higher Mexican orientation than the normative sample (see Table 5). In order to examine the relation between parental/family functioning and acculturation, one-tailed correlations between the psychometrically-sound, translated measures (i.e., PSOC, APQ subscales of Involvement and Positive Parenting, and CHAOS) and the Mexican and Anglo orientations as measured by the ARSMA-II were computed. As shown in Table 6, the PSOC was positively related to the MOS $(r=0.25, p<0.05)$ and Involvement was positively related to the MOS $(r=0.24, p<0.05)$; a trend towards significance also was found between the CHAOS and AOS $(r=0.20, p<0.10)$.

Table 5 Means and Standard Deviations for the PSOC, APQ, CHAOS, and ARSMA-II

\begin{tabular}{|c|c|c|c|c|}
\hline & \multicolumn{4}{|c|}{ Current sample Original sample } \\
\hline & $\mathbf{M}$ & (SD) & M & (SD) \\
\hline PSOC & 4.90 & $(0.70)$ & $\mathrm{N} / \mathrm{A}$ & \\
\hline APQ involvement & 41.50 & (5.04) & 40.42 & $(4.43)$ \\
\hline APQ positive parenting & 26.75 & $(3.08)$ & 25.67 & (2.64) \\
\hline APQ poor monitoring/supervisior & 17.57 & $(5.30)$ & 12.28 & $(3.36)$ \\
\hline APQ inconsistent discipline & 13.13 & $(4.30)$ & 13.90 & (3.30) \\
\hline APQ corporal punishment & 4.90 & $(1.42)$ & 5.58 & $(1.61)$ \\
\hline CHAOS & 34.91 & $(10.33)$ & $\mathrm{N} / \mathrm{A}$ & \\
\hline AOS & 2.71 & $(0.75)$ & 3.82 & $(0.57)$ \\
\hline MOS & 4.43 & $(0.40)$ & 3.28 & $(0.84)$ \\
\hline
\end{tabular}

The normative means and standard deviations were not available for the PSOC and CHAOS; means and standard deviations for the English version of the APQ are from Dadds et al. 2003. Due to the nature of the measure, results of the ARSMA-II were only examined with parents of Mexican descent $(N=58)$. The normative data (means and standard deviations) for the previous sample came from Cuéller et al. 1995 
NOT THE PUBLISHED VERSION; this is the author's final, peer-reviewed manuscript. The published version may be accessed by following the link in the citation at the bottom of the page.

Table 6 Correlations for the PSOC, APQ, and CHAOS with AOS and MOS

\begin{tabular}{|l|l|l|}
\hline & AOS & MOS \\
\hline PSOC & 0.16 & $0.25^{*}$ \\
\hline APQ involvement & 0.06 & $0.24^{*}$ \\
\hline APQ positive parenting & 0.02 & 0.04 \\
\hline CHAOS & $0.20^{+}$ & -0.06 \\
\hline
\end{tabular}

Due to the nature of the questions, results of the ARSMA-II were only examined with parents of Mexican descent $(N=58) .{ }^{+} p \leq 0.10,{ }^{*} p \leq 0.05$

\section{Discussion}

Overall, the Spanish translations of the CHAOS and PSOC, as well as the APQ subscales of Involvement and Positive Parenting, demonstrated good reliability and construct validity with a sample of Spanish-speaking, Latino parents. Additionally, the PSOC and the APQ subscale of Involvement demonstrated good cultural validity; a trend towards significance also suggested initial evidence for the cultural validity of the CHAOS. Thus, in general, results suggest that these parental/family functioning measures are psychometrically and culturally appropriate for use with Spanish-speaking, Latino families.

\section{Psychometric Properties}

As predicted, the Spanish translation of the CHAOS, a measure of chaos in the home, demonstrated good reliability and construct validity. Specifically, the scale revealed good internal consistency, as well as good convergent validity by demonstrating positive relationships with theoretically-related measures of parenting stress and child externalizing behaviors. Furthermore, the CHAOS demonstrated good concurrent validity by reliably distinguishing between children with and without clinically significant externalizing behaviors. Specifically, parents who reported higher levels of chaos in the home were more likely to report clinically elevated levels of externalizing behaviors in their children. This is consistent with the original, English version of the CHAOS that has been shown to have good reliability and positive correlations with parenting stress and child externalizing behaviors (Dumas et al. 2005).

Journal of Abnormal Child Psychology, Vol 39, No. 1 (2011): pg. 33-43. DOI. This article is @ Springer and permission has been granted for this version to appear in e-Publications@Marquette. Springer does not grant permission for this article to be further copied/distributed or hosted elsewhere without the express permission from Springer. 
Similarly, predictions related to the reliability and construct validity of the Spanish translation of the PSOC, a measure of parenting efficacy, were supported. In addition to good internal consistency, the scale demonstrated good convergent validity; it was negatively related to theoretically-related measures of parenting stress and child externalizing behaviors. This is not surprising given that similar findings emerged for the original version of the PSOC. Specifically, previous literature has demonstrated a negative relationship between parenting efficacy and child externalizing problems, as well as between parenting efficacy and parenting stress (e.g., Gerdes et al. 2007; Johnston and Mash 1989). Contrary to our prediction and to findings for the English version of the PSOC, the Spanish translation of the PSOC failed to demonstrate good concurrent validity in that it was unable to reliably distinguish between children displaying clinically significant externalizing behaviors from those who were not displaying such behaviors.

There are several possible explanations for this finding. Consistent with a community sample, only eight children in the current sample were found to display clinical elevations in externalizing behaviors. Other researchers have pointed out that psychometric studies examining the ability of a clinical measure to predict risk factors for childhood disorders often run into difficulties, as many community samples do not contain adequate numbers of "clinical cases" (Rubio-Stipec et al. 1990). Additionally, examination of the standard error of the PSOC revealed a relatively high variance as compared to the other measures in the current study. Since logistic regression analyses seek to identify the amount of variance of an outcome (e.g., externalizing behaviors or not) as accounted for by a predictor (e.g., parenting efficacy), the more error variance a predictor has, the less likely it is to yield a significant regression (Tabachnick and Fidell 2007). Thus, despite the significant correlation found between the PSOC and externalizing behaviors, only $1 \%$ of the variability (as demonstrated by Cox and Snell and Nagelkerke $\mathrm{R}^{2}$ values) in clinically significant externalizing behaviors was explained by the PSOC. Despite the fact that good convergent validity could not be established with the current sample, other findings revealed that not only is the Spanish translation of the PSOC reliable, it also has good convergent validity.

Journal of Abnormal Child Psychology, Vol 39, No. 1 (2011): pg. 33-43. DOI. This article is @ Springer and permission has been granted for this version to appear in e-Publications@Marquette. Springer does not grant permission for this article to be further copied/distributed or hosted elsewhere without the express permission from Springer. 
Finally, findings related to the reliability and construct validity of the Spanish translation of the APQ varied depending on the subscale, with subscales measuring positive parenting being more psychometrically sound than those measuring negative parenting. Specifically, Involvement and Positive Parenting were found to demonstrate good reliability and construct validity. Both resulted in good internal consistency and convergent validity. Specifically, Involvement and Positive Parenting were negatively related to theoretically-related measures of parenting stress and child externalizing behaviors. Both subscales also demonstrated good concurrent validity by reliably distinguishing between children displaying clinically significant externalizing behaviors. Specifically, parents who reported higher levels of Involvement and Positive Parenting were less likely to report clinical elevations of externalizing behaviors in their children. This is consistent with previous literature examining the English version of the APQ that has demonstrated good reliability for the positive parenting subscales (i.e., Involvement and Positive Parenting), as well as a negative relation between these scales and child externalizing problems (e.g., Shelton et al. 1996).

On the other hand, Poor Monitoring/Supervision, Inconsistent Discipline, and Corporal Punishment resulted in less than optimal reliability (i.e., $\leq 0.70$ ), and Poor Monitoring/Supervision and Inconsistent Discipline also failed to demonstrate good construct validity in the current sample. Specifically, examination of convergent validity of the APQ subscales of Poor Monitoring/Supervision and Inconsistent Discipline revealed that they were not significantly correlated with parenting stress or externalizing behaviors. Additionally, examination of concurrent validity of the APQ subscales of Poor Monitoring/Supervision and Inconsistent Discipline revealed that they did not reliably distinguish between children on the CBCL/6-18.

It is important to note that while the internal inconsistencies for Poor Monitoring/Supervision and Corporal Punishment are slightly lower than would be considered optimal, they are similar to the internal consistencies reported for the English version (Dadds et al. 2003). However, contrary to previous studies examining the original $A P Q$, the current study also found less evidence for the construct validity of the negative parenting subscales (i.e., Inconsistent Discipline, Poor Monitoring/Supervision, and Corporal Punishment) 
relative to the positive parenting subscales (e.g., Dadds et al. 2003; Shelton et al. 1996). This is partially due to the lower reliability that was found for these subscales in the current study, which made it more difficult to attain good validity (Cronbach and Meehl 1955; Sattler 2001). It also is possible that parents are less consistent and accurate reporters of their own negative parenting behaviors due to an underlying desire to self-monitor and/or self-protect. Specifically, parents in research settings may fear disclosure of negative parenting behaviors because of concern that they will be viewed by researchers as "bad parents" and/or concern that the researchers will report potential child abuse, which was explicitly stated in the current study's consent form.

With regards to the Spanish version of the APQ, it also is possible that cultural factors may explain why the negative parenting subscales demonstrated lower reliability and validity than the positive parenting subscales. It is possible that the constructs of poor monitoring/supervision and inconsistent discipline are not as relevant for Latino families as they may be for Caucasian families. Examination of means and standard deviations indicate that the current sample of Latino parents reported less parental monitoring than English-speaking samples (e.g., Dadds et al. 2003). Unlike European-American families who tend to operate mainly within the immediate family, Latino families tend to be more collectivist and rely more on their extended family and community for childcare and support (Altarriba and Bauer 1998; Cauce and Domenech-Rodriguez 2002). Therefore, it is quite possible that Latino parents report directly monitoring their children less, because their children are being adequately supervised by other members of their extended family or community. Similarly, examination of the items on the Inconsistent Discipline subscale reveals that the scale inquires about consistency in giving and enforcing discipline strategies, such as time out and removal of privileges. While these are common discipline strategies in European American families (Regalado et al. 2004), Latino families are much more likely to use discipline strategies that involve corporal punishment, such as spanking (see Halgunseth et al. 2006 for a review; Monzo and Rueda 2006). Future work is clearly needed, but it is possible that the items that make up the Poor Monitoring/Supervision and Inconsistent Discipline scales of the APQ

Journal of Abnormal Child Psychology, Vol 39, No. 1 (2011): pg. 33-43. DOI. This article is @ Springer and permission has been granted for this version to appear in e-Publications@Marquette. Springer does not grant permission for this article to be further copied/distributed or hosted elsewhere without the express permission from Springer. 
may be less relevant to Latino families and may need to be modified for use with Spanish-speaking, Latino families.

\section{Cultural Properties}

In general, results examining the cultural properties of the psychometrically-sound, translated measures suggest that the Spanish translations of the PSOC and the APQ subscale of Involvement demonstrated good cultural validity in that they correlated with theoretically-related measures of Anglo and Mexican orientation. Specifically, higher Mexican orientation was related to greater parenting efficacy and more parental involvement, which is consistent with past research demonstrating the "familism," or an emphasis on the closeness of the family, consistent discipline, and a strong family hierarchy, is a core Latino value (Miranda et al. 2006; Miranda et al. 2000; Rodriguez et al. 2007). Additionally, initial evidence for the cultural validity of the CHOAS was supported by a trend suggesting that higher Anglo orientation was related to higher levels of family chaos, which may be explained by the acculturative stress that Latino families often face when adapting to a new culture (Finch and Vega 2003; Gil and Vega 1996; Miranda et al. 2006; Miranda et al. 2000; Sullivan et al. 2007).

\section{Limitations and Future Directions}

The current study provides progress toward providing culturallyappropriate assessments for Latino families. Results suggest that thorough translation procedures, as well as examination of psychometric and cultural properties can provide solid evidence for the use of Spanish translations of parental/family functioning measures with Spanish-speaking, Latino parents. Several limitations of the current study should be noted. First, although the study attempted to recruit both mothers and fathers, fathers remained underrepresented in the final sample, which needs to be a focus of future work. Similarly, due to the demographics of Latinos in Southeast Wisconsin and the inclusion criterion that parents speak Spanish, the current study resulted in parents who were primarily of Mexican descent and who may have been less acculturated than the general Latino population. Subsequently, although Berry's Model of Acculturation 
(Berry 1980, 1997, 2006) which identifies four groups (i.e., assimilationist, separationist, marginalist, and integrationist) based on the status of orientation towards one's traditional and host cultures was of interest to the authors, this model could not be sufficiently examined due to the limited range of acculturation displayed in the current sample. Given the diversity of the Latino population, future studies should seek to examine these predictions in other Latino subcultures, as well as with other Latino samples with greater variability in acculturation status. Finally, the nature of a community sample resulted in a limited amount of childhood psychopathology, making predictions related to concurrent validity difficult to test. Extending the current findings to a clinical sample would be beneficial.

\section{Footnotes}

${ }^{1}$ It should be noted that only 2 parents had children who were five years of age. Their data was not included in analyses examining the APQ or CBCL/618 , since these measures are normed for parents of children who are at least six years of age (Achenbach and Rescorla 2001; Shelton et al. 1996).

2Due to busy parental schedules, several parents needed to leave the session prior to completing their packets. These parents either completed the remainder of their packets over the phone with a bilingual research assistant or returned their own packet via mail. Analyses were run with and without data from these parents, and the pattern of findings remained the same.

\section{References}

Abidin, R. R. (1982). Parenting stress and the utilization of pediatric services. Children's Health Care, 2, 70-73.

Achenbach, T. M., \& Rescorla, L. A. (2001). Manuel for the ASEBA school-age forms \& profiles. Burlington: University of Vermont, Research Center for Children, Youth, \& Families.

Alegría, M., Mulvaney-Day, N., Woo, M., Torres, M., Gao, S., \& Oddo, V. (2007). Correlates of past-year mental health service use among Latinos: results from the National Latino and Asian American Study. American Journal of Public Health, 97, 76-83.

Altarriba, J., \& Bauer, L. M. (1998). Counseling the Hispanic client: Cuban Americans, Mexican Americans, and Puerto Ricans. Journal of Counseling and Development, 76, 389-396.

Journal of Abnormal Child Psychology, Vol 39, No. 1 (2011): pg. 33-43. DOI. This article is (C) Springer and permission has been granted for this version to appear in e-Publications@Marquette. Springer does not grant permission for this article to be further copied/distributed or hosted elsewhere without the express permission from Springer. 
American Psychiatric Association. (2000). Diagnostic and statistical Manuel of mental disorders, Fourth Edition, Text Revision (DSM$I V-T R)$. Washington, DC: American Psychiatric Association.

Berry, J. W. (1980). Acculturation as varieties of adaptation. In A. Padilla (Ed.), Acculturation: Theory, models and findings (pp. 925). Boulder: Westview.

Berry, J. W. (1997). Immigration, acculturation and adaptation. Applied Psychology, 46, 5-68.

Berry, J. W. (2006). Acculturation: A conceptual overview. In M. H. Bornstein \& L. R. Cote (Eds.), Acculturation and parent-child relationships. Mahwah: Earlbaum.

Bornstein, M. H., \& Cote, L. R. (2006). Acculturation and parent-child relationships. Mahwah: Earlbaum.

Brislin, R. W. (1970). Back-translation for cross-cultural research. Journal of Cross-Cultural Psychology, 1, 185-216.

Brislin, R., Lonner, W., \& Thorndike, R. (1973). Cross-cultural research methods. New York: Wiley.

Callejas, L., Nesman, R., Mowery, D., \& Garnache, P. (2006). Research with Latino populations. In M. Hernandez et al. (Eds.), Examining the research base supporting culturally competent children's mental health services (pp. 83-116). Tampa: Louis de la Parte Florida Mental Health Institute.

Cauce, A. M., \& Domenech-Rodriguez, M. (2002). Latino families: Myths and realities. In J. M. Conteras, K. A. Kerns, \& A. M. NealBarnett (Eds.), Latino children and families in the United States: Current research and future directions (pp. 3-25). Westport: Praeger.

Chronis, A. M., Lahey, B. B., Pelham, W. E., Kipp, H. L., Baumann, B. L., \& Lee, S. S. (2003). Psychopathology and substance abuse in parents of young children with attention deficit/hyperactivity disorder. Journal of the American Academy of Child and Adolescent Psychiatry, 42, 1424-1432.

Chronis, A. M., Chacko, A., Fabiano, G. A., Wymbs, B. T., \& Pelham, W. E. (2004). Enhancements to the Behavioral Parent Training paradigm for families of children with ADHD: Review and future directions. Clinical Child and Family Psychology Review, 7, 1-27.

Clark, L. A., \& Watson, D. (1995). Constructing validity: basic issues in objective scale development. Psychological Assessment, 7, 309319.

Journal of Abnormal Child Psychology, Vol 39, No. 1 (2011): pg. 33-43. DOI. This article is @ Springer and permission has been granted for this version to appear in e-Publications@Marquette. Springer does not grant permission for this article to be further copied/distributed or hosted elsewhere without the express permission from Springer. 
Cortina, J. M. (1993). What is coefficient alpha? An examination of theory and applications. The Journal of Applied Psychology, 78, 98-104.

Crawford, A. N. (Ed.). (1984). A Spanish language Fry-type readability procedure: Elementary level. In Bilingual Education Paper Series. Los Angeles: Evaluation, Dissemination, and Assessment Center.

Cronbach, L. J. (1951). Coefficient alpha and the internal structure of tests. Psychometrika, 16, 297-334.

Cronbach, L. J., \& Meehl, P. E. (1955). Construct validity in psychological tests. Psychological Bulletin, 52, 281-302.

Cuéller, I., Arnold, B., \& Maldonado, R. (1995). Acculturation rating scale for Mexican Americans-II: a revision of the original ARSMA scale. Hispanic Journal of Behavioral Sciences, 17, 275-304.

Cunningham, C. E., \& Boyle, M. H. (2002). Preschools at risk for attention-deficit hyperactivity disorder and oppositional defiant disorder: family, parenting, and behavioral correlates. Journal of Abnormal Child Psychology, 30, 555-569.

Dadds, M. R., Maujean, A., \& Fraser, J. A. (2003). Parenting and conduct problems in children: Australian data and psychometric properties of the Alabama Parenting Questionnaire. Australian Psychologist, 38, 238-241.

Dumas, J. E., Nissley, J., Nordstrom, A., Smith, E. P., Prinz, R. J., \& Levine, D. W. (2005). Home chaos: sociodemographic, parenting, interactional, and child correlates. Journal of Clinical Child and Adolescent Psychology, 34, 93-104.

Dupaul, G. J., McGoey, K. E., Eckert, T. L., \& VanBrakle, J. (2001). Preschool children with attention-deficit/hyperactivity disorder: impairments in behavioral, social, and school functioning. Journal of the American Academy of Child and Adolescent Psychiatry, 40, 508-515.

Essau, C. A., Sasagawa, S., \& Frick, P. J. (2006). Psychometric properties of the Alabama parenting questionnaire. Journal of Child and Family Studies, 15, 597-616.

Finch, B. K., \& Vega, W. A. (2003). Acculturation stress, social support, and self-rated health among Latinos in California. Journal of Immigrant Health, 5, 109-117.

Flesch, R. (1948). A new readability yardstick. The Journal of Applied Psychology, 32, 221-233.

Journal of Abnormal Child Psychology, Vol 39, No. 1 (2011): pg. 33-43. DOI. This article is @ Springer and permission has been granted for this version to appear in e-Publications@Marquette. Springer does not grant permission for this article to be further copied/distributed or hosted elsewhere without the express permission from Springer. 
Flores, G., Guentes-Afflick, E., Barbot, O., Carter-Pokras, O., Claudio, L., Lara, M., et al. (2002). The health of Latino children: urgent priorities, unanswered questions, and a research agenda. Journal of the American Medical Association, 288, 82-90.

Fry, E. (1968). A readability formula that saves time. Journal of Reading, 11, 513-516.

Fry, E. (1977). Fry's readability graph: clarifications, validity, and extension to level 17. Journal of Reading, 21, 242-252.

Fuligni, A. J. (1998). Authority, autonomy, and parent-adolescent conflict and cohesion: a study of adolescents from Mexican, Chinese, Filipino, and European backgrounds. Developmental Psychology, 34, 782-792.

Gerdes, A. C., Hoza, B., Arnold, L. E., Pelham, W. E., Swanson, J. M., Wignal, T., et al. (2007). Maternal depressive symptomotology and parenting behavior: exploration of possible mediators. Journal of Abnormal Child Psychology, 35, 705-715.

Gil, A. G., \& Vega, W. A. (1996). Two different worlds: acculturation stress and adaptation among Cuban and Nicaraguan families. Journal of Social and Personal Relationships, 13, 435-456.

Haack, L. M., Gerdes, A. C., Cruz, B., \& Schneider B. W. (2010). Culturally modified recruitment strategies for Latino families in clinical child research: A critical first step. Manuscript submitted for publication.

Halgunseth, L. C., Ispa, J., \& Ruddy, D. D. (2006). Parental control in Latino families: an integrative review. Child Development, 77, 1282-1297.

Johnston, C., \& Mash, E. (1989). A Measure of parenting satisfaction and efficacy. Journal of Clinical Child Psychology, 18, 167-175.

Johnston, C., \& Mash, E. J. (2001). Families of children with attentiondeficit/hyperactivity disorder: review and recommendations for future research. Clinical Child and Family Psychology Review, 4, $183-207$.

Kataoka, S. H., Zhang, L., \& Wells, K. B. (2002). Unmet need for mental health care among U.S. children: variation by ethnicity and insurance status. The American Journal of Psychiatry, 159, 1548-1555.

Keown, L. J., \& Woodward, L. J. (2002). Early parent-child relations and family functioning of preschool boys with pervasive

Journal of Abnormal Child Psychology, Vol 39, No. 1 (2011): pg. 33-43. DOI. This article is @ Springer and permission has been granted for this version to appear in e-Publications@Marquette. Springer does not grant permission for this article to be further copied/distributed or hosted elsewhere without the express permission from Springer. 
hyperactivity. Journal of Abnormal Child Psychology, 30, 541553.

Matheny, A. P., Wachs, T. D., Ludwig, J. L., \& Phillips, K. (1995). Bringing order out of chaos: psychometric characteristics of the confusion, hubbub, and order scale. Journal of Applied Developmental Psychology, 16, 429-444.

Messick, S. (1995). Validity of psychological assessment: validation of inferences from persons' responses and performances as scientific inquiry into score meaning. The American Psychologist, 50, 741-749.

Mio, J. S., Hackett-Barker, L., \& Tumambing, J. (2006). In S. Rutter (Ed.), Multicultural psychology: Understanding our diverse communities. Boston: McGraw-Hill.

Miranda, A. O., Estrada, D., \& Firpo-Jimenez, M. (2000). Differences in family cohesion, adaptability, and environment among Latino families in dissimilar stages of acculturation. The Family Journal, $8,341-350$.

Miranda, A. O., Bilot, J. M., Peluso, P. R., Berman, K., \& Van Meek, L. G. (2006). Latino families: the relevance of the connection among acculturation, family dynamics, and health for family counseling research and practice. The Family Journal, 14, 268273.

Monzo, L. D., \& Rueda, R. (2006). A socio-cultural perspective on acculturation: Latino immigrant families negotiating diverse discipline practices. Education and Urban Society, 38, 88-203.

Murphy, K. R., \& Barkley, R. A. (1996). Parents of children with attention-deficit/hyperactivity disorder: psychological and attentional impairment. American Journal of Orthopyschiatry, 66, 93-102.

Okagaki, L., \& Sternberg, R. J. (1993). Parental beliefs and children's school performance. Child Development, 64, 36-56.

Peifer, K. L., The-wei, H., \& Vega, W. (2000). Help seeking by persons of Mexican origin with functional impairments. Psychiatric Services, 51, 1293-1298.

Pelham, W. E. (2002). Attention deficit hyperactivity disorder: Diagnosis, assessment, nature, etiology, and treatment. Unpublished manuscript, State University of New York at Buffalo.

Journal of Abnormal Child Psychology, Vol 39, No. 1 (2011): pg. 33-43. DOI. This article is @ Springer and permission has been granted for this version to appear in e-Publications@Marquette. Springer does not grant permission for this article to be further copied/distributed or hosted elsewhere without the express permission from Springer. 
Pelham, W. E., Fabiano, G. A., \& Massetti, G. M. (2005). Evidencebased assessment of attention deficit hyperactivity disorder in children and adolescents. Journal of Clinical Child and Adolescent Psychology, 34, 449-476.

Reddy, L. A., \& de Thomas, C. (2007). In S. R. Smith \& L. Handler (Eds.), The clinical assessment of children and adolescents: $A$ practitioner's handbook. New Jersey: Erlbaum.

Regalado, M., Sareen, H., Wissow, L. S., \& Halfon, N. (2004). Parents' discipline of young children: results from the National Survey of Early Childhood Health. Pediatrics, 113, 1952-1958.

Rodriguez, N., Mira, C., Paez, N., \& Myers, H. (2007). Exploring the complexities of familism and acculturation: Central constructs for people of Mexican origin. American Journal of Community Psychology, 39, 61-77.

Rubio-Stipec, M., Bird, H., Canino, G., \& Gould, M. (1990). The internal consistency and concurrent validity of a Spanish translation of the child behavior checklist/6-18. Journal of Abnormal Child Psychology, 18, 393-396.

Sattler, J. M. (2001). Assessment of children: Cognitive applications (4th ed.). San Diego: Jerome M. Sattler.

Schill, L., Schwab-stone, M., Merikangas, K. R., Leckman, J. F., Zhang, H., \& Kasl, S. (1999). Psychosocial and clinical correlates of ADHD in a community sample of school-age children. Journal of the American Academy of Child and Adolescent Psychiatry, 38, 976-983.

Shelton, K. K., Frick, P. J., \& Wootton, J. (1996). Assessment of parenting practices in families of elementary school-age children. Journal of Clinical Child Psychology, 25, 317-329.

Shelton, T. L., Barkley, R. A., Crosswait, C., Moorehous, M., Fletcher, K., Barrett, S., et al. (1998). Psychiatric and psychological morbidity as a function of adaptive disability in preschool children with aggressive and hyperactive-impulsive-inattentive behavior. Journal of Abnormal Child Psychology, 26, 475-494.

Smith, B. H., Barkley, R. A., \& Shapiro, C. J. (2006). Attentiondeficit/hyperactivity disorder. In E. J. Mash \& R. A. Barkley (Eds.), Treatment of childhood disorders (3rd ed., pp. 65-136). New York: Guildford.

Smokowski, P. R., Chapman, M. V., \& Bacallao, M. L. (2007). Acculturation risk and protective factors and mental health

Journal of Abnormal Child Psychology, Vol 39, No. 1 (2011): pg. 33-43. DOI. This article is @ Springer and permission has been granted for this version to appear in e-Publications@Marquette. Springer does not grant permission for this article to be further copied/distributed or hosted elsewhere without the express permission from Springer. 
symptoms in immigrant Latino adolescents. Journal of Human Behavior in the Social Environment, 16, 33-55.

Solis, M. L., \& Abidin, R. R. (1991). The Spanish version parenting stress index: a psychometric study. Journal of Clinical Child Psychology, 20, 1991.

Sullivan, S., Schwartz, S. J., Guillermo, P., Huang, S., Pantin, H., \& Szapocznik, J. (2007). A bidimensional model of acculturation for examining differences in family functioning and behavior problems in Hispanic immigrant adolescents. The Journal of Early Adolescence, 27, 405-430.

Tabachnick, B. G., \& Fidell, L. S. (2007). Using multivariate statistics (5th ed., pp. 437-505). Boston: Pearson Education.

U.S. Census Bureau. (2000). Retrieved March 23, 2007 from http:// factfinder.census.gov.

U.S. Department of Health and Human Services. (2001). Mental health: Culture, race, and ethnicity-a supplement to mental health: A report of the surgeon general. Rockville: U.S. Department of Health and Human Services, Substance Abuse and Mental Health Services Administration, Center for Mental Health Services.

Vega, W. A., \& Lopez, S. R. (2001). Priority issues in Latino mental health services research. Mental Health Services Research, 3, 189-200.

Yeh, M., McCabe, K., Hough, R. L., Dupuis, D., \& Hazen, A. (2003). Racial/ethnic differences in parental endorsement of barriers to mental health services for youth. Mental Health Services Research, 5, 65-77. 